\title{
INTERNET USAGE IN THE FRESH PRODUCE SUPPLY CHAIN IN CHINA
}

\author{
Xiaoxiao $\mathrm{Xu}^{1}$, Yanqing Duan ${ }^{1, *}$, Zetian $\mathrm{Fu}^{2}{ }^{2}$, Xue Liu ${ }^{2}$ \\ ${ }^{1}$ University of Bedfordshire Business School, UK \\ ${ }^{2}$ China Agricultural University, PR China \\ * Corresponding author: Prof Yanqing Duan, University of Bedfordshire Business School, \\ Park Square,Luton,LU1 3JU, UK, Yanqing.duan@beds.ac.uk.
}

\begin{abstract}
Although effective implementation of the Internet technologies has a great potential for improving efficiency and reducing wastage within the fresh produce supply chain. the situation of the Internet usage by SMEs (small and medium sized enterprises) in the fresh produce supply chain is still unclear in China. As the main players, SMEs haven't been given enough attention from both academics and governments. Therefore, this research attempts to address this issue by, first, investigating the current usage of the Internet and related software by Chinese SMEs in the fresh produce supply chain, and then, by identifying enablers and barriers faced by SMEs to call government's attention. As a part of an EU-Asia IT\&C funded project, a survey was carried out with SMEs in this industry from five major cities in China. The results reveal that in the relatively developed areas of China, SMEs in the fresh produce supply chain are rapidly adopting the Internet and software packages, but the level of adoption varies greatly and there is a significant lack of integration among the supply chain partners. Chinese SMEs are keen to embrace emerging technologies and have acted to adopt new software and tools. Given that cost of implementation is not a barrier, their concern over legal protection and online security must be addressed for further development.
\end{abstract}

Key words: Internet technologies, fresh produce supply chain, supply chain software and tools, small and medium sized enterprises (SMEs), China.

Please use the following format when citing this chapter:

Xu, X., Duan, Y., Fu, Z. and Liu, X., 2009, in IFIP International Federation for Information Processing, Volume 295, Computer and Computing Technologies in Agriculture II, Volume 3, eds. D. Li, Z. Chunjiang, (Boston: Springer), pp. 2151-2160. 


\section{INTRODUCTION}

China is the biggest agricultural country in Asia and its entry to the WTO has further increased its influence. As the fastest developing country, China is currently experiencing dramatic changes in almost all industry areas, and it is facing the most challenging changes in agriculture, especially in the fresh produce sector. Having been traded in the street market and wholesale market for hundred years in China (Datamonitor, 2006), fresh produces are converting into the sales channels owned by supermarket, influenced by international multi-retailers, such as Carrefour and Walmart. There is also a call from the government to facilitate this change, as customers can benefit from food safety traceability, guaranteed produce quality, and a relatively cleaner shopping environment (Ministry of Agriculture of the People's Republic of China, 2006).

The Internet and information technologies play a critical role in helping SMEs (small and medium sized enterprises) to embrace the technological challenges and improve the business competitiveness in a global market. However, several issues, such as concerns over the online security, low level of users' skills, cost of implementation, lack of legal protection of online transaction and lack of awareness of using technologies, discourage SMEs to adopt and use the Internet and related software. Funding from the Europe Asia IT\&C programme by European Commission was granted to a project called VEGNET: 'Enhancing Vegetable Supply Chain Management with Internet Technologies' (http://vegnet.beds.ac.uk/vegnet). The aim of this project was to transfer managerial and technological know-how to Chinese SMEs from Europe and to introduce supply chain management concepts and the use of Internet technologies to support supply chain management (SCM) in Chinese agri-businesses.

The research presented in this paper aims to analyse the current Internet usage in the fresh produce supply chain in China, to benchmark the supply chain management status for Chinese fresh produce companies, and to evaluate the factors influencing the Internet usage in the fresh produce industry. The results provide a contemporary overview of the current development, pinpoint the issues in the Internet adoption and usage in Chinese agribusiness, and provide suggestions for future research and practice.

\section{IMPORTANCE OF SMES IN THE FRESH PRODUCE SUPPLY CHAIN}

Chinese government has put tremendous efforts on so-called "informatisation" to enable people in agriculture obtain in-time information 
from the market, especially for those in remote rural areas. The development of agricultural websites grew rapidly since 1998, which include government websites, educational websites, and commercial websites (Xiang et al., 2006). From all agricultural websites, commercial websites owned by companies are $82.6 \%$ in 2003 (Yang et al., 2003), and progressed to 84\% in 2006 (Xiang et al., 2006). However, those data did not differentiate the contributions made by SMEs.

Chinese publications indicate that most agribusiness companies are SMEs, and recognize the importance of SMEs in a macro-economic point of view (Li, 2000). However, there is no clear indication of the percentage of agribusiness SMEs in the industry. A scholar, Mr. Zhou (Zhang, 2003) complained about inconsistence in statistics of SMEs among different departments of the central government. More ironically, China SMEs Online, the official SMEs department of China, did not cover the SMEs in agriculture in its national "Survey Report of Informatisation in Chinese SMEs (SME online, 2006). Those facts demonstrate that agribusiness SMEs are ignored by previous research in terms of "informatisation", although they are believed to be important for the agriculture industry.

Previous research is mostly based on anecdotal evidence when analyzing the role of the Internet in agriculture (Wang and Liu, 2005), benefits that the Internet can bring to farmers (Wan, 2007), difficulties of farmers to accept it, and suggestions to promote Internet usage by farmers (Tian and Chen, 2006). Those literatures may serve as a good foundation to propose ideas, but no empirical investigations have been conducted to find out the situation of SMEs acceptance of the Internet, what factors enable them to use it, and what factors discourage their usage. This research aims to fill this gap by conducting a survey study with SMEs in the fresh produce supply chain and attempts to reflect the current situation on the adoption of Internet technologies. Findings shed light on the current situation on the use and further development of Internet technologies along the Chinese fresh produce supply chain and provide valuable implications for Chinese government and policy makers.

\section{METHODOLOGY}

\subsection{Survey design}

The questionnaire contained three sections. Section one collected information about the company and respondent profile, including the role of the company in the fresh produce industry, company size, business scope, managers' understanding and skills. Section two was about the technology 
issues of the company, such as the software used in the supply chain, Internet functions, the identification of the development level, and level of Internet-based supply chain development etc. Section three dealt with the internal and external factors influencing the level of Internet usage. A fivepoint scale was used to measure the degree of the influence factors.

\subsection{Survey administration}

The survey was targeted at SMEs in the Chinese fresh produce supply chain, including growers/ farmers, food processors/ manufacturers, wholesalers, importers/exporters, retailers and transporters. Because the definition of SMEs in China varies by industries (not including agriculture) (China SME online, 2003), it is difficult to follow. To be comparable with the data in the UK survey, we define a SME as a company with 10 to 250 employees, by adopting the definition by the UK Department for Business, Enterprise and Regulatory Reform (BERR, formerly DTI), which is also a widely accepted definition in the EU.

The survey was conducted by using a data collection service in China, who carried out a Computer Assist Telephone Interview (CATI) in 5 representative cities in China, covering five major representative cities, Beijing (North), Shanghai (East), Guangzhou (South), Chengdu (West), and Wuhan (Central), with 30 samples from each city. From the data provided by the service, overall 2,995 companies were contacted. Every effort was made to reach a diverse but valid sample group. 151 valid responses were received, which gave a $5 \%$ overall response rate. By listening to the interview recordings, the authors gained tremendous information about the viewpoint of agribusiness managers in China. In this paper, quotes are provided wherever possible for a further explanation.

\subsection{Profile of respondents}

The responses covered almost all of the players in the fresh produce industry in China. A majority of them come from wholesaler (68\%) grower/ farmer $(55 \%)$, and retailer $(52 \%)$, and the rest of them come from food processor / manufacturer (27\%), transporter (17\%) and importer/ exporter (17\%). Most SMEs play a multiple role in the supply chain. For example, some of the SMEs have their internal vertical integration by participating in growing, manufacturing, wholesaling and retailing. However, most growers and wholesalers outsourced transportation service to a third party.

The questionnaire was required to be completed by the company owners and managing directors, or by other senior managers who had a broad knowledge of the fresh produce supply chain operation and information systems presently used. From the responses, $66 \%$ of the replies were from 
company owners, CEOs, or managing directors, while $16 \%$ were completed by logistics/supply chain/operation directors and $18 \%$ were answered by IT managers or others.

According to BERR's definition, we included businesses with a current headcount of up to 249 staff employed directly by the business. This clarification is critical, since in the fresh produce industry, most companies employed temporary/ casual/ seasonal staff. About $40 \%$ of the respondents belong to medium sized companies (50-249 employees), while there were $60 \%$ of the surveyed companies are small companies (10-49 employees).

\section{SURVEY RESULTS}

\subsection{Current use of Internet technologies}

The situation of the use of Internet technologies is covered by mainly two parts, Internet and website application, and related software packages.

As shown in Table 1, only $7 \%$ of the companies have no Internet applications, while email systems and online communication tools are very common for the surveyed SMEs. The respondents believe that these tools are much easier and cheaper than traditional ways of communication, and they can also obtain more product and price information by contacting prospective customers through the online communication tools such as QQ, MSN (with overseas partners) or other tools developed by online marketplaces such as Alibaba. The usage of Intranet and Extranet are limited compared with other usages.

Table 1 Internet Applications in China's Fresh Produce SMEs

\begin{tabular}{ccccc}
\hline Internet Applications & & & Website Functions \\
Email system & $83 \%$ & & Company information & $97 \%$ \\
Online communication tools & $77 \%$ & & Products information & $96 \%$ \\
Company website & $59 \%$ & & Online ordering & $53 \%$ \\
Intranet & $36 \%$ & & Customer account management & $33 \%$ \\
Extranet & $30 \%$ & & Online payment & $30 \%$ \\
No Internet & $7 \%$ & & Supplier account management & $28 \%$ \\
\hline
\end{tabular}

More than half of the companies have company websites, and most of the websites contain company information and product information. Over half of the respondent companies provide online ordering functions. Some of them also manage their online payment and customer and supplier accounts on the Internet. From their own explanations, they usually have an account in the 
online marketplace such as Alibaba, which hosts a homepage of their company. Orders are redirected from their website to the online marketplace to be processed. However, most deals are made after face-to-face meeting or phone calls. They express their concern over the authenticity of online information.

There are some companies, which had bad experiences in online trading. When asked if they have online communication tools or a company website, here are some examples of responses: "I don't trust any information online." "It is too easy for people to cheat online. Nobody would know that other people are telling lies". "You will never see a real price online."

Regarding the use of the supply chain management software (Table 2), results show that the technologies are becoming accepted by a limited group of SMEs. Of the software packages currently used, Barcode systems (31\%) and WMS (warehouse management system) (30\%) are the most popular, while GTS (geo-code track system) (11\%) and RFID (radio frequency identification) (9\%) are least popular by fresh produce companies.

Results also show that Chinese agribusiness managers have a limited knowledge of supply chain software packages, for example they argued that "we are just growing/selling vegetable/ fruits, and those high technologies are not possible to use." They haven't realized the possible impact that those emerging technologies could bring, and still believe that agribusiness ought to be not technology driven. For many of them, it was their first time to hear those software names or explanations.

Table 2 Software Used in SMEs

\begin{tabular}{cccccccccc}
\hline & $\begin{array}{c}\text { Barcode } \\
\text { systems }\end{array}$ & WMS & CRM & EDI & AQC & TMS & ERP & GTS & RFID \\
\hline Currently using & $31 \%$ & $30 \%$ & $27 \%$ & $23 \%$ & $19 \%$ & $15 \%$ & $12 \%$ & $11 \%$ & $9 \%$ \\
Plan to use in 2 years & $19 \%$ & $13 \%$ & $22 \%$ & $18 \%$ & $19 \%$ & $16 \%$ & $16 \%$ & $12 \%$ & $7 \%$ \\
'lan to use over 2 year: & $8 \%$ & $14 \%$ & $8 \%$ & $10 \%$ & $9 \%$ & $10 \%$ & $19 \%$ & $11 \%$ & $13 \%$ \\
No plan to use & $23 \%$ & $19 \%$ & $25 \%$ & $26 \%$ & $27 \%$ & $31 \%$ & $29 \%$ & $29 \%$ & $42 \%$ \\
No need to use & $15 \%$ & $18 \%$ & $14 \%$ & $14 \%$ & $15 \%$ & $25 \%$ & $15 \%$ & $31 \%$ & $17 \%$ \\
Don't know & $5 \%$ & $6 \%$ & $4 \%$ & $8 \%$ & $11 \%$ & $3 \%$ & $10 \%$ & $6 \%$ & $12 \%$ \\
\hline
\end{tabular}

Please note that a full explanation of the software list can be found in Duan et al. (2007).

Looking at the future, companies have little intention to use RFID, as $42 \%$ of them had no plan to use the system, $17 \%$ of them felt no need to use it. CRM (customer relationship management) is more likely to be used in two years. In the longer term, ERP (enterprise recourse planning) is more likely to be used. It is also quite common that many respondents felt hard to clarify their future plans, though they were at the top management of the companies.

"Whether to use any software could not be decided by me. I have to see the trend of the industry." 
"It is my first time to hear those strange words. I have to decide whether to use them according to the development of my company as well. Our company is still small, not like the big companies.'

"I usually contact our trade partners by telephone, and seldom use the Internet. I don't trust anything online."

"Fresh produce business is quite different from others. You have to see the real products. Every orange is different, even though they grow in the same plant. You have to see them by your own eyes. It is impossible to have online transaction for this type of business. The Internet just works as a marketing tool."

\subsection{Factors affecting Internet adoption}

The results presented in Table 3 and 4 show the perceived motivators and barriers of using the Internet by Chinese agribusiness managers.

Managers believe that "Pressure from market competition" is the biggest driver for them to use the Internet. Some managers commented that "the real benefit that the Internet could bring to us is really limited, but we really have to be present online as a marketing strategy." "Geographic scope of the company" is ranked in the second place, because companies feel that the large scope of their business within China or Asia enables them to use the Internet with more prospective clients. However, companies feel less "Pressure from customers and suppliers", because it is unlikely to lose a customer or supplier only because of not using the Internet. They explained that they are very flexible in using the technologies, no matter what tools their clients use.

Table 3 Motivators of Internet Usage

\begin{tabular}{llll}
\hline Motivators & $\mathrm{N}$ & Mean & S.D \\
\hline Pressure from market competition & 145 & 3.84 & 1.27 \\
The geographic scope of your company & 144 & 3.39 & 1.21 \\
The nature of the fresh produce industry & 147 & 3.26 & 1.41 \\
Government provided incentives & 145 & 3.17 & 1.38 \\
Perceived benefits of IT implementation & 147 & 3.16 & 1.21 \\
Pressure from top management & 146 & 3.00 & 1.36 \\
Bank requirements for transactions & 142 & 2.95 & 1.41 \\
Pressure from customers for integration & 145 & 2.90 & 1.34 \\
High complexity of business operation & 143 & 2.81 & 1.28 \\
Pressure from suppliers for integration & 143 & 2.66 & 1.31 \\
\hline
\end{tabular}

Regarding barriers to the Internet adoption, a very strong concern of legal protection and security issues are demonstrated by Chinese SMEs. Many respondents expressed their concern over security. Most managers reflected 
their dissatisfactions with those out-of-date and poor qualities of the information online. They also regarded the lack of know-how and training as significant barriers. For example, in one of the cases in Wuhan, the local government helped farmers to launch a website for them to sell fresh produce, but the manager complained that the government people only teach them basic IT skills, without any commercial information of the trend of the market, and they have no idea where to find this information.

Table 4 Barriers of Internet Usage

\begin{tabular}{lccc}
\hline Barriers & $\mathrm{N}$ & $\mathrm{Mean}$ & $\mathrm{S}$. D \\
\hline Inadequate legal protection for online trade & 147 & 3.24 & 1.33 \\
Concern over Internet security & 149 & 3.19 & 1.42 \\
Lack of know-how & 148 & 2.99 & 1.35 \\
Lack of training & 147 & 2.87 & 1.32 \\
Resistance to changes of adopting the Internet in the supply chain & 146 & 2.77 & 1.37 \\
Lack of collaborative partners & 149 & 2.68 & 1.28 \\
Lack of trust in trading partners & 147 & 2.65 & 1.40 \\
Poor IT infrastructure & 144 & 2.65 & 1.36 \\
Reluctance of sharing information & 143 & 2.50 & 1.37 \\
Cost of implementation & 145 & 2.30 & 1.28 \\
\hline
\end{tabular}

Surprisingly, "Cost of implementation" and "Poor IT infrastructure" are ranked as the least barriers to Internet adoption. Their comments not only reflect their limited understanding of the cost of Internet implementation, but also reinforce the fact that the concern over Internet security discourages their usage of the Internet. The managers commented that "Computers and Internet access are not a problem for us. Paying money to online marketplace is also not a big deal. But all we are worried is how much genuine information we will be able to obtain? We don't want to spend money for rubbish information."

\section{DISCUSSION AND CONCLUSION}

This paper represents a key part of a research effort in understanding the current situation and promoting a better adoption of Internet technologies in the Chinese fresh produce supply chain.

Literature reviews reveal a lack of investigation of Internet technology usage by SMEs in the fresh produce industry. By using a survey approach, this paper provides both qualitative and quantitative information on the current development in the use of ICTs in the fresh produce supply chain in China. The paper also helps to identify the key motivators and barriers of the Internet usage in Chinese SMEs. 
The findings from the survey interviews show that fresh produce SMEs are using the Internet to communicate via online tools. SMEs perform well in using the online marketplaces for information searching. There are more SMEs doing online business transactions compared with those in the UK (Duan et al., 2007). In terms of supply chain software, a small group of SMEs are using online software, but most SMEs do not have any intention to use software or emerging technologies. They haven't realized that supply chain software packages play a key role in improving website functionalities and internal supply chain efficiency.

Market competition is the most significant driver for SMEs. To survive in the very competitive business environment, companies have to have an online presence to attract more potential customers. Pressures from their trade partners seem not to be a major driver for the Internet adoption.

Cost of implementation and poor IT infrastructure of the Internet have been considered as barriers by previous research in Western countries (Peng, 2005, Wang and Liu, 2005, Chen, 2005), but this research reveals that among all the barriers, cost of implementation is considered as the least important one, while poor IT infrastructure is considered as the third least one. In contrary, lack of legal protection and concern over Internet security are considered as the biggest barriers by SMEs. Several Chinese publications also mentioned that the government should develop appropriate laws to protect online transaction (Peng, 2005, Feng, 2007). The findings also suggest that Chinese SMEs are keen to embrace emerging technologies and have acted to adopt new software and tools. Given that cost of implementation is not a big barrier, their concern over legal protection and online security must be addressed by policy makers and the government.

It should be noted that the above findings are based on the survey in 5 large cities in China, and may not represent SMEs in other small cities and less developed remote regions. However, the research findings have a significant contribution to a better understanding of Internet applications in agriculture sector and new knowledge on factors affecting the technology adoption and further development. Findings also offer practical guidelines and managerial implications to agribusiness mangers and government policy makers.

\section{ACKNOWLEDGEMENTS}

This research is partially funded by European Commission's Euro Asia ITC program (CN/ASIA-IT\&C/005 (89099). The authors would like to acknowledge the financial support of EC and all the project partners for their collaboration and contribution. 


\section{REFERENCES}

Chen, X. (2005) Exploitation and Utilization of Agricultural Information Resource under Network Environment- Focus on Network Exploitation and Construction of models Used by Farmers. Journal of Library and Information Sciences in Agriculture, 17, pp. 56-58.

China SME online (2003) Temporary Definition of SME, http://www.sme.gov.cn/web/assembly/action/browsePage.do?channelID=1172982990367 \&contentID=1172982990524,SME Department of National Development and Reform Commission of P.R. China.

Datamonitor (2006) Food Retail in China. Datamonitor.

Duan, Y., Xu, X., Liu, X., Fu, Z., Zografos, K. \& Bemeleit, B. (2007) Accelerating Internet Adoption in China's Fresh Produce Supply Chain: a VEGNET Approach. New Zealand Journal of Agricultural Research, 50, pp. 1299-1305

Feng, W. (2007) Research on E-business in Agriculture. Wenzhou Agriculture Technology, 1, pp. 20-21 and 45 .

Li, Z. (2000) How to Transfer Surplus Labour in Rural Area in China, http://www.ncer.tsinghua.edu.cn/research/trend/papers/27.htm, accessed by Jun 1st, 2008

Ministry of Agriculture of the People's Republic of China (2006) Design and Plan for Agriproduct Market System for the "11th Five Year" Period, http://www.agri.gov.cn/xztz/t20061212_738312.htm, Department of Market and Economic information

Peng, J. (2005) A Brief Discussion on How to Develop E-commerce in China's Agricultural Corporations. Research in Agricultural Mechanisation 4, pp. 54-56.

SME online (2006) Survey report of Informatisation of Chinese SMEs, http://www.sme.gov.cn/web/assembly/action/browsePage.do?channelID=1154936200894 \&contentID=1154936201212, SME Department of National Development and Reform Commission of P.R. China.

Tian, M. \& Chen, H. (2006) Problems and Solutions of the Development of E-business in Agriculture in China. Jiangxi Agriculture Academic, 18, pp. 203-204.

Wan, Q. (2007) Research on the Electronic Commerce of Agriculture. Agriculture Network Information, 9, pp. 113-114.

Wang, X. \& Liu, Y. (2005) Using E-business to Improve the Development of Agri-business. Economist, 7, pp.185 and 187.

Xiang, J., Xiao, L., Meng, X., Cui, L., Xiao, N. \& Jin, C. (2006) The Situation and Evaluation of china Agriculture Information Website Development. Agriculture Network Information, 2.

Yang, X., Jia, S. \& Zhao, Y. (2003) Current Situation and Evaluation of Agricultural Websites in China. Computer and Agriculture, 9, 19.

Zhang, L. (2003) How Many SMEs are There in China? http://www.china.com.cn/chinese/OP-c/421148.htm, accessed by May 31st, 2008 